\title{
IRIS MAMMILLATIONS: SIGNIFICANCE AND ASSOCIATIONS
}

\author{
NICOLA K. RAGGE ${ }^{1,2}$, J. ACHESON ${ }^{2}$ and A. LINN MURPHREE ${ }^{1}$ \\ Los Angeles and London
}

\begin{abstract}
SUMMARY
Iris mammillations are rarely described, distinctive villiform protuberances that can cover the iris. In the majority of reported cases they are unilateral and sporadic, and are seen in association with oculodermal melanosis. In past literature and current clinical practice they are frequently confused with the iris nodules seen in neurofibromatosis type 1 . Their clinical significance is not established, although it has been suggested that iris mammillations may be an external sign of ocular hypertension or intraocular malignancy. We report a series of 9 patients between the ages of 3 and 28 years with iris mammillations. The mammillations appear as regularly spaced, deep brown, smooth, conical elevations on the iris, of uniform height or increasing in height as the pupil margin is approached. They often overlie a naevus or an exceptionally deeply pigmented iris, such as that seen in melanosis oculi. One case had an associated ciliary body mass. They tend to occur in more highly pigmented ethnic groups and can be dominantly inherited. Iris mammillations may occur in association with systemic conditions including phakomatosis pigmentovascularis type IIb and neurofibromatosis type 1 when they may even coexist with iris hamartomas.
\end{abstract}

Iris mammillations are highly distinctive villiform elevations that can partially or totally carpet the anterior surface of the iris. The affected iris or part of the iris has a dark, velvety appearance to the naked eye. The term 'mammillations' (or mamillations) appears to be derived from the initial description by Coats in 1912, when he described the 'mammillated appearance to the surface of the iris' of a patient with melanosis oculi ${ }^{1}$ (Fig. 6a). The term 'mammillated' is derived from the Latin meaning covered with

From: ${ }^{1}$ Division of Ophthalmology, Children's Hospital Los Angeles, and Department of Ophthalmology, USC School of Medicine, Los Angeles, California, USA; ${ }^{2}$ Western Eye Hospital, St Mary's Hospital Trust, London, UK.

Correspondence to: Nicola Ragge, MA, MRCP, FRCOphth, Western Eye Hospital, Marylebone Road, London NW1 5YE, UK. mammiform (nipple- or teat-like) protuberances.

Iris mammillations are an occasional finding with few previous reports. They are most commonly found in association with melanosis oculi $1,{ }^{1-6}$ with or without periocular skin involvement in a naevus of Ota. They are thus often less precisely referred to as iris melanosis, a term which should best be reserved for increased pigmentation of the iris, irrespective of the presence of iris elevations overlying the pigmented areas. ${ }^{7}$ This is supported by the rare descriptions of iris elevations in the absence of any increased iris pigmentation. ${ }^{7,8}$

Iris mammillations are usually unilateral, often presenting as heterochromia iridis. Occasional bilateral cases have been described. ${ }^{7,8}$ Iris mammillations usually occur sporadically, although familial cases have been described. ${ }^{7}$ Although iris mammillations are symptomatic, their occurrence has been associated with ocular hypertension ${ }^{7}$ and intraocular malignancies. ${ }^{1}$

In this report we describe the appearances of iris mammillations and associated ocular and extraocular conditions in a series of 9 individuals from various ethnic backgrounds.

\section{CASE REPORTS}

The case reports are summarised in Table I.

\section{Case 1}

An 8-year-old white girl presented with blurring of vision during a school eye check. She had visual acuities of right eye $20 / 20$ with $-3.00 /+1.00 \times 110^{\circ}$ and left eye $20 / 20$ with $-3.25 /+0.75 \times 65^{\circ}$. She had a unilateral iris naevus with overlying dark brown, small conical elevations of uniform height. Bilateral myopic crescents were seen around the optic nerves. She had no other pigmentary abnormalities.

\section{Case 2}

An 8-year-old hispanic girl presented at the age of 2 years with multiple congenital anomalies including 
Table I. Summary of ocular findings and associated conditions in 9 individuals with iris mammillations

\begin{tabular}{|c|c|c|c|c|c|c|c|c|c|}
\hline $\begin{array}{l}\text { Case } \\
\text { no. }\end{array}$ & $\begin{array}{c}\text { Age } \\
\text { (years) } \\
\text { and sex }\end{array}$ & Ethnic origin & $\begin{array}{l}\text { Melanosis } \\
\text { oculi }\end{array}$ & $\begin{array}{l}\text { Ocular } \\
\text { involve- } \\
\text { ment }\end{array}$ & $\begin{array}{l}\text { Iris } \\
\text { involve- } \\
\text { ment }\end{array}$ & $\begin{array}{l}\text { Underlying } \\
\text { naevus }\end{array}$ & Visual problems & $\begin{array}{l}\text { Other associated } \\
\text { conditions }\end{array}$ & $\begin{array}{l}\text { Illustration } \\
\text { (Fig. no.) }\end{array}$ \\
\hline 1 & $8 \mathrm{~F}$ & Caucasian & $\mathrm{N}$ & $\mathrm{U}$ & $\mathrm{P}$ & $\mathrm{Y}$ & Myopia & None & \\
\hline 2 & $8 \mathrm{~F}$ & Hispanic & $\mathrm{N}$ & B & $\mathrm{T}$ & $\mathrm{N}$ & High myopia & $\begin{array}{l}\text { CHD, cleft palate, } \\
\text { marfanoid habitus }\end{array}$ & 1 \\
\hline 3 & $9 \mathrm{M}$ & Hispanic & $\mathrm{Y}$ & $\mathrm{U}$ & $P$ & Y & $\begin{array}{l}\text { Esotropia and } \\
\text { amblyopia of other } \\
\text { eye }\end{array}$ & Seizures & 2 \\
\hline 4 & $20 \mathrm{M}$ & Asian-Indian & $\mathrm{Y}$ & B & $P$ & $\mathbf{N}$ & Iris hamartomas & $\begin{array}{l}\text { Neurofibromatosis } \\
\text { type } 1\end{array}$ & 3 \\
\hline 5 & $7 F$ & Hispanic & $\mathrm{N}$ & B & ST & $\mathrm{N}$ & Optic neuritis & $\begin{array}{l}\mathrm{TB}, \text { frontal } \\
\text { arachnoid cyst }\end{array}$ & 4 \\
\hline 6 & $10 \mathrm{~F}$ & Middle Eastern & $\mathrm{Y}$ & B & $\mathrm{T}$ & $\mathrm{N}$ & $\begin{array}{l}\text { Calcified ciliary } \\
\text { body mass }\end{array}$ & $\begin{array}{l}\text { Mother also had } \\
\text { bilateral iris } \\
\text { elevations }\end{array}$ & \\
\hline 7 & $5 \mathrm{~F}$ & Hispanic & $\mathrm{Y}$ & B & $\mathrm{T}$ & $\mathrm{N}$ & $\begin{array}{l}\text { Congenital } \\
\text { glaucoma }\end{array}$ & $\begin{array}{l}\text { Phakomatosis } \\
\text { pigmentovascularis } \\
\text { IIb }\end{array}$ & $\left(\right.$ Published $\left.^{9}\right)$ \\
\hline 8 & $28 \mathrm{M}$ & Asian Indian & $\mathrm{N}$ & B & ST & $\mathrm{N}$ & None & None & \\
\hline 9 & $3 \mathrm{M}$ & N. African & $\mathrm{Y}$ & B & $\mathrm{T}$ & $\mathrm{N}$ & None & $\begin{array}{l}\text { Ectopic Mongolian } \\
\text { spot, preauricular } \\
\text { skin tag, abnormal } \\
\text { rib }\end{array}$ & 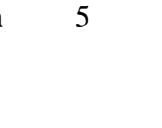 \\
\hline
\end{tabular}

M, male; F, female; Y, yes; N, no; U, unilateral; B, bilateral; P, partial; T, total; ST, subtotal; CHD, congenital heart disease.

cleft palate, congenital heart disease and high myopia. Physical examination revealed pectus excavatum, marfanoid habitus and hyperextensibility of her joints with a possible diagnosis of Stickler syndrome. Ocular examination showed visual acuities of right eye $20 / 50$ with $-14.75 /+0.50 \times 120^{\circ}$ and left eye $20 / 40$ with $-17.50 /+0.50 \times 170^{\circ}$. She had bilateral villiform iris elevations completely covering the anterior surface of both irides (Fig. 1). She also had bilateral posterior staphylomata, but no pigmentary abnormalities on the sclera, fundus or the skin.

\section{Case 3}

A 9-year-old hispanic boy with a history of seizures, treated with phenobarbitone, presented with right esotropia and amblyopia. He had corrected visual acuities of right eye $20 / 30$ with $+1.50 /+0.50 \times 51^{\circ}$ and left eye 20/20 with plano. He had an esotropia of 16 prism dioptres in the distance and 25 prism dioptres at near. The slit lamp examination revealed a small patch of scleral melanosis at the limbus at 5 o'clock and a diffuse iris naevus with overlying multiple villiform elevations in the left eye only (Fig. 2). There were also tunica vasculosa lentis remnants in both eyes, more marked on the right. The right eye and both fundi showed no abnormal pigmentary changes.

\section{Case 4}

A 20-year-old Asian Indian male presented at the age of 15 years with multiple café au lait patches, freckling, coarse facial features and mental retardation. A diagnosis of neurofibromatosis type 1 was made. On ocular examination he had visual acuities of right eye $20 / 20$ with $+0.75 /+0.25 \times 90^{\circ}$ and left eye $20 / 20$ with $+1.50 /+0.50 \times 90^{\circ}$. On slit lamp examination he was noted to have two distinct types of iris nodules. There was a carpet of profuse, regularly spaced conical elevations the same colour as the underlying brown iris, as well as a few, paler iris hamartomas (Fig. 3). He had mild pigmentation of the perilimbal sclera. Fundus examination was normal.

Case 5

A 7-year-old hispanic girl was recovering from bilateral asymmetrical optic neuritis. She also had a frontal arachnoid cyst, which had been drained, and a positive TB test for which she was receiving isoniazid. Ocular examination showed visual acuities of 20/40 unaided in both eyes, with minimal dyschromatopsia. She had bilateral multiple villiform elevations overlying a green-brown iris (Fig. 4). Fundus examination showed resolving mild disc swelling in the right eye and a normal appearance on the left.

\section{Case 6}

A 10-year-old Middle Eastern girl was visiting the United States for follow-up of a non-progressive calcified ciliary body mass of unknown aetiology in the right eye. She had no other medical history of note. Visual acuities were right eye $20 / 30$ with plano/ $+2.50 \times 120^{\circ}$ and left eye $20 / 25$ with $+2.00 /+2.00 \times 75^{\circ}$. Slit lamp evaluation showed on the right eye three small perilimbal pigmented patches on the sclera at 3 o'clock and one further patch at 6 o'clock. There was a large, very dark brown iris naevus, with overlying iris elevations, involving all the iris except the sector between 12 o'clock and 3 o'clock, which was the regular dark brown colour, the same as the other eye. The iris was pushed forward by a retroirideal mass and there was iridocorneal touch at 10 o'clock. There 


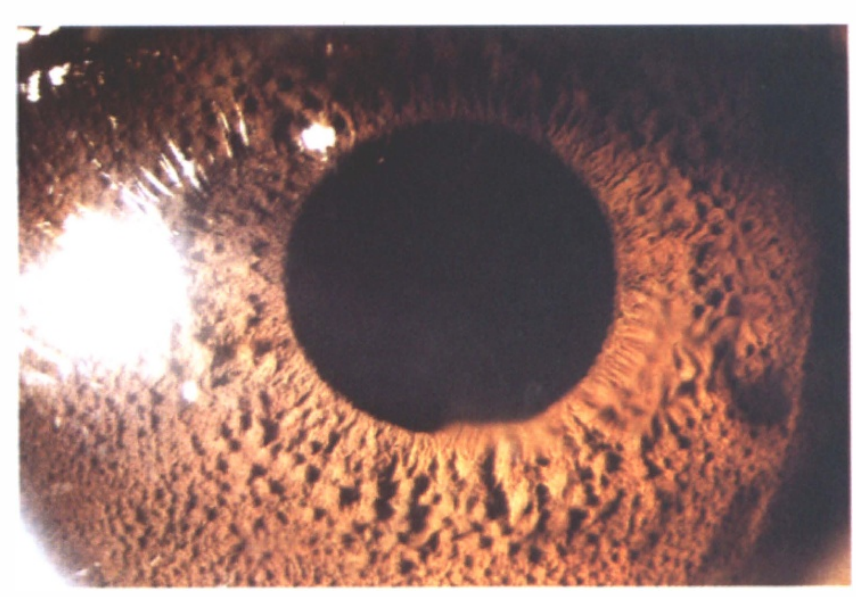

(a)

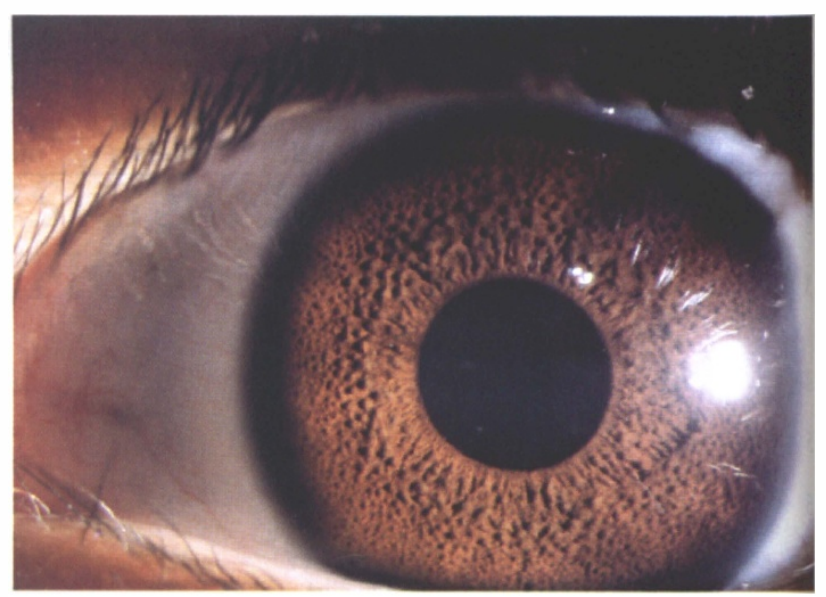

(b)

Fig. 1. Case 2. Iris mammillations: detail of the right eye (a) and the left eye (b).

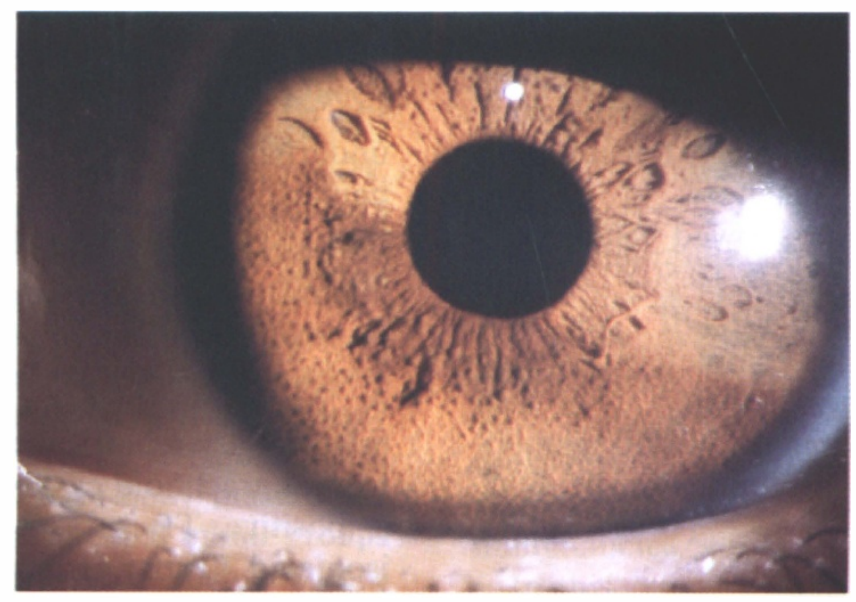

Fig. 2. Case 3. Iris mammillations overlying naevus.

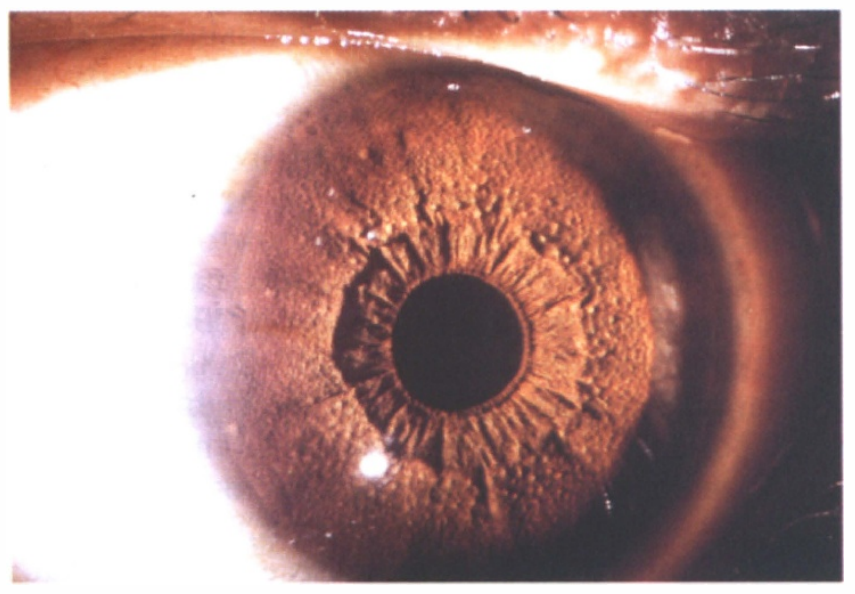

(a)

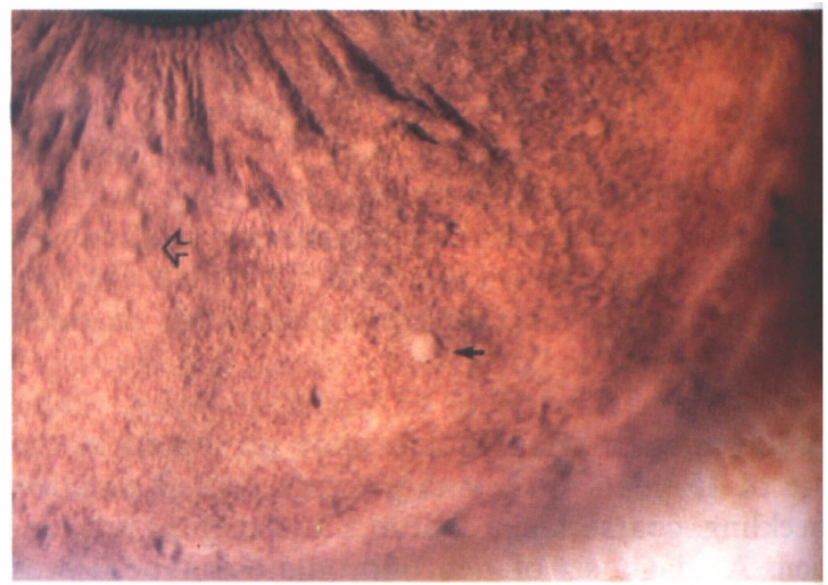

(b)

Fig. 3. Case 4. Iris mammillations (open arrow) and iris hamartomas (filled arrow) in a patient with neurofibromatosis 1 . 


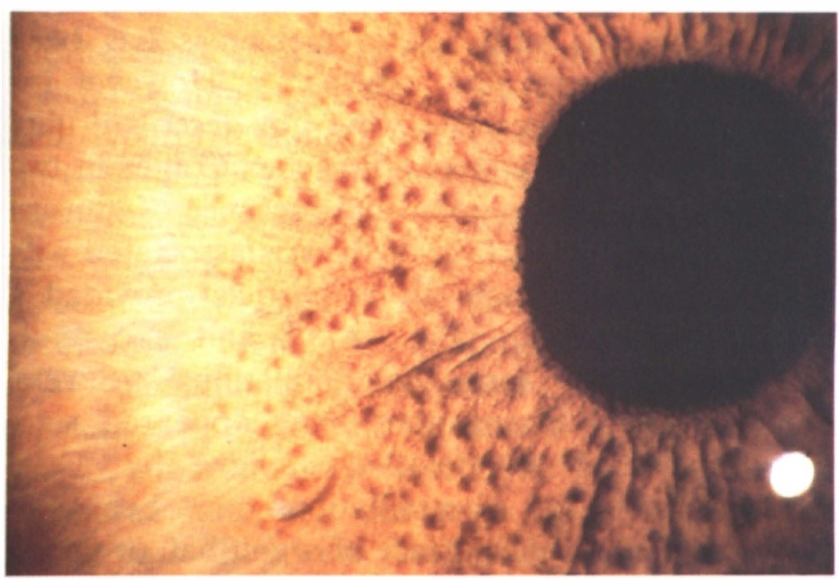

(a)

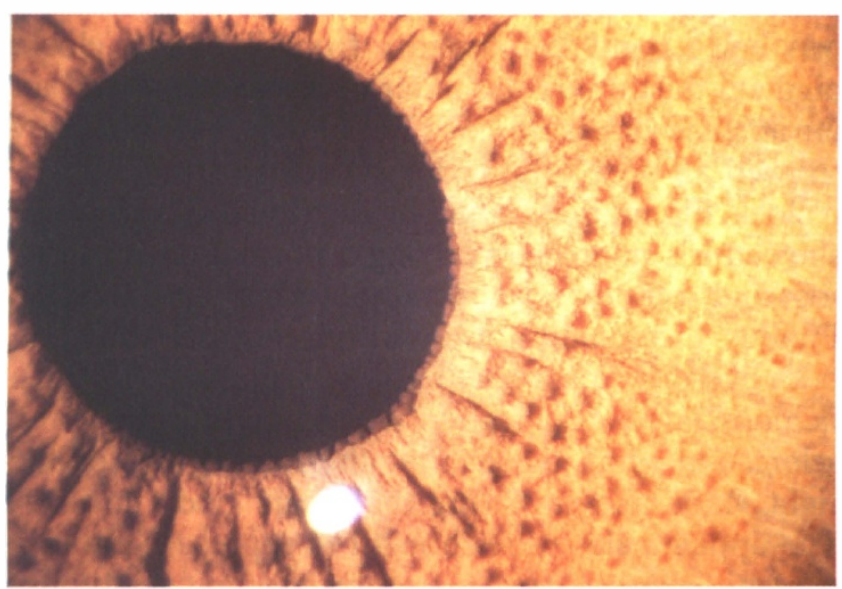

(b)

Fig. 4. Case 5. Right (a) and left (b) eye in a patient with bilateral iris mammillations.

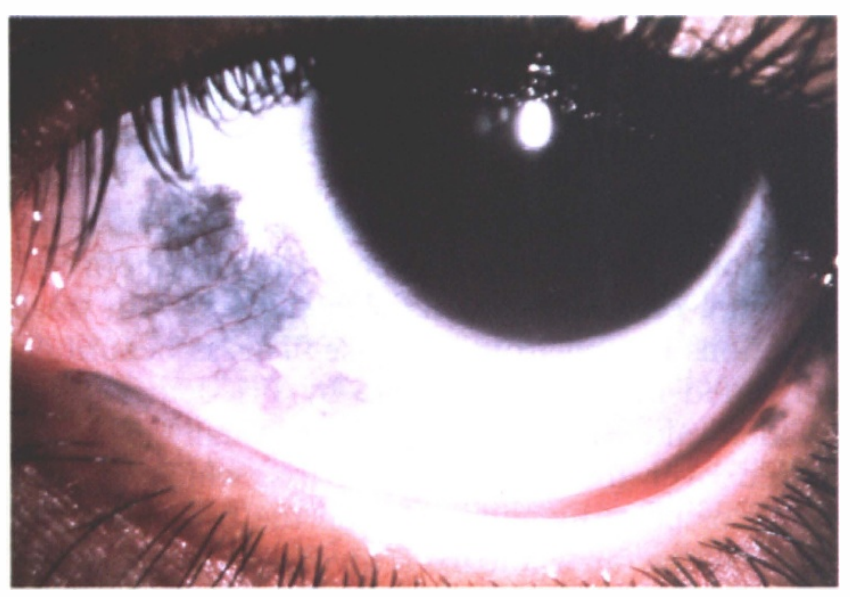

(a)

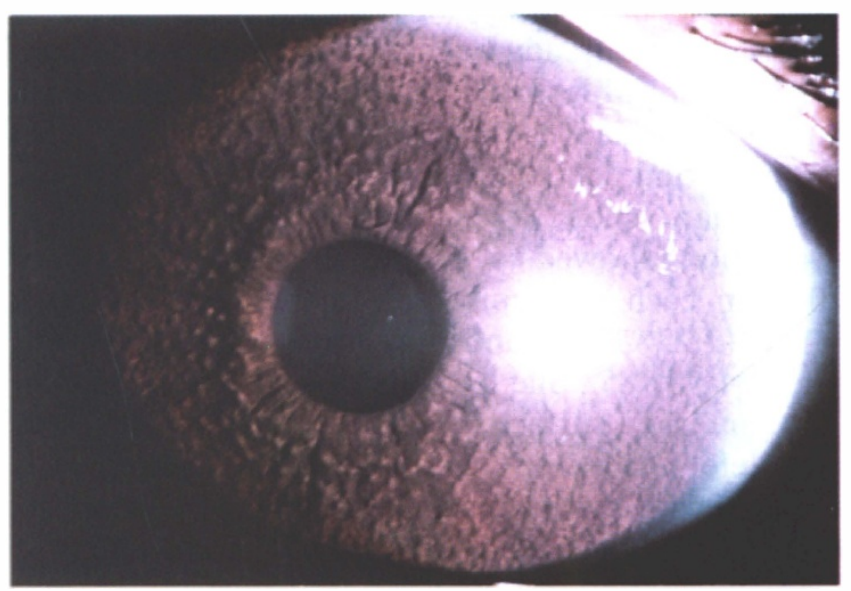

(b)

Fig. 5. Case 9. Scleral melanosis (a) and iris mammillations (b).

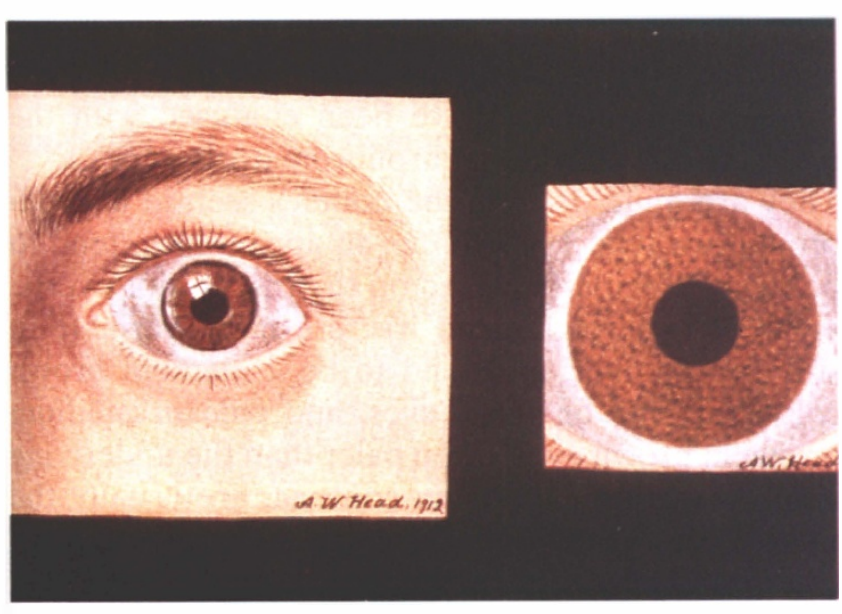

(a)

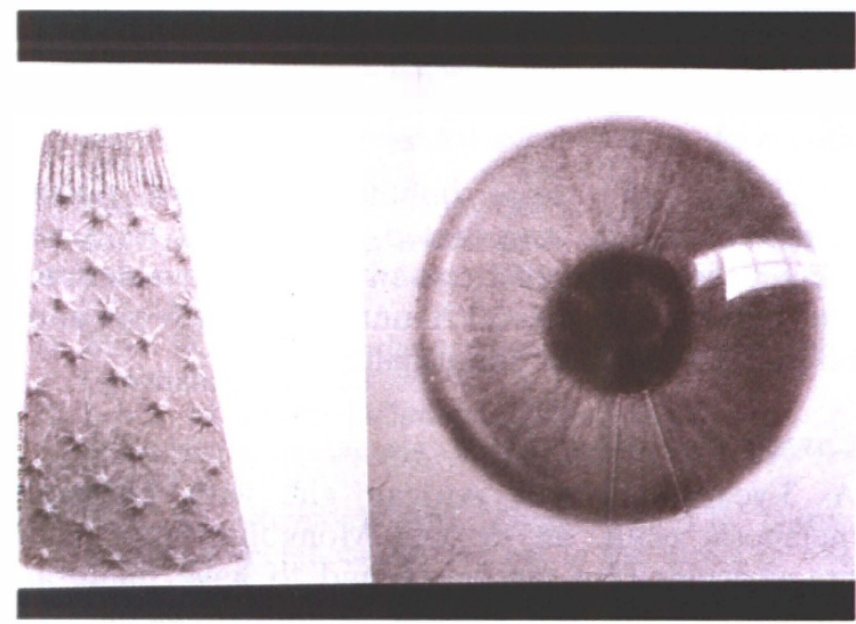

(b)

Fig. 6. Early illustrations of iris mammillations reproduced from: (a) Coats' article in $1912^{1}$ and (b) the article by Friedenwald and Friedenwald in $1925 .^{4}$ 
was early band keratopathy from 7 to 9 o'clock, pigment dusting on the anterior lens surface and an intraocular pressure of $16 \mathrm{mmHg}$. Gonioscopy showed an area of anterior synechiae from 7 to 11 o'clock, but no mass could be identified. The left eye showed iris nodules overlying a normal dark brown iris and otherwise a totally normal appearance. Fundus examination was within normal limits in both eyes; the mass could not be visualised. CT scan demonstrated calcification of the right retina and sclera extending throughout the lateral half of the right globe and involving the ciliary body and iris. The appearances were thought to represent either a parasitic process or a neurofibroma, but no biopsy has been performed. Both parents underwent ocular examinations and the mother was also found to have bilateral iris mammillations.

\section{Case 7}

This case has already been published in detail. ${ }^{9}$

A 5-year-old hispanic girl presented at birth with an extensive naevus flammeus on her face and also on her trunk and extremities, as well as ectopic Mongolian spots over her body. Ophthalmic evaluation showed a corrected visual acuity of $20 / 30$ in each eye, corrected in the right eye with $-1.00 /+1.25 \times 100^{\circ}$ and in the left eye with $+0.50 /+0.75 \times 85^{\circ}$. She had bilateral scleral melanosis. The anterior surface of both brown irides was completely covered with regularly spaced iris nodules with the typical appearance of mammillations. She had evidence of congenital glaucoma with enlarged corneal diameter at 13-14 mm on the right and $11-12 \mathrm{~mm}$ on the left, borderline raised intraocular pressures and bilateral optic disc cupping ( $50 \%$ on the right and $40 \%$ on the left). There was bilateral pigment dusting on the anterior lens surface and a high iris insertion into the angle. She had no evidence of other ocular pigmentation or haemangioma.

\section{Case 8}

A 28-year-old trainee ophthalmologist of Asian Indian extraction was noted incidentally to have bilateral iris mammillations on slit lamp evaluation. He had visual acuities 20/20 unaided in each eye and no associated ocular abnormality.

\section{Case 9}

A 3-year-old North African girl with bilateral melanosis oculi, an ectopic Mongolian spot and pre-auricular skin tag was found to have bilateral iris mammillations on slit lamp examination (Fig. 5). She had normal acuities.

\section{DISCUSSION}

The association of an ipsilateral variegated or very dark brown iris with scleral melanosis has been described in several early articles. ${ }^{10-15}$ However, iris mammillations themselves were not described until 1912 when both Coats and Treacher Collins in two neighbouring articles noted the presence of unusual elevations on the surface of the iris associated with melanosis oculi. Coats in his article provided a beautiful illustration (Fig. 6a) $)^{1,16}$ and apparently first coined the term 'mammillations'. 'Several other excellent descriptions have appeared since then, including a detailed review by François. ${ }^{2,4,5,7,8,17,18}$ Iris mammillations have been variously likened to 'the surface of a golf ball or gooseskin', a 'field of stubble or a deforested landscape where only the stumps of trees remain,4 and 'irregularities on the surface of tripe or of an Indiarubber sponge'. ${ }^{19}$ They are presumed to be congenital, although the youngest age at which they have been described appears to be 2 years old. ${ }^{19}$ There may be an increase in incidence of scleral melanosis during puberty, but the late onset of iris mammillations in a previously unaffected iris has never been recorded.

Our cases illustrate several features of iris mammillations. Their shape appears to be smooth and villiform, conical, or sometimes stellate, with small radiations issuing from the base. This is beautifully illustrated in the 1925 article by Friedenwald and Friedenwald $^{4}$ (Fig. 6b). They are usually regularly spaced over the surface of an iris, which may be totally or partially involved as in the two cases with naevi. When the whole iris is involved, the elevations tend to increase in size gradually as the pupillary margin is approached. When they overlie a naevus, they are more uniform in height. The iris underlying the mammillations may be more deeply pigmented than normal. This may be seen as very deep brown irides or brownish coloration towards the pupil, iris heterochromia in unilateral cases, or a variegated appearance in sector involvement or naevi.

Iris mammillations have been confused with the iris nodules seen in neurofibromatosis type 1.,20 They are quite distinct: the nodules seen in neurofibromatosis type 1 are fluffier in appearance, tend to be more irregularly placed on the iris; do not overlie areas of hyperpigmented iris; are more variable in size and number; and tend to be a medium brown colour in blue or green eyes, and pale or medium brown in brown eyes, often paler than the underlying iris. Iris mammillations, in contrast, are usually the same colour as the underlying iris in brown eyes and medium brown in blue or green eyes. The comparison is well illustrated in case 4 where both are present (Fig. 3).

Although the terms have been used interchangeably in the past, it is worth differentiating between iris melanosis and iris mammillations. ' Iris melanosis 
can be considered as hyperpigmentation of the iris, which is commonly associated with scleral melanosis and hyperpigmentation of the choroid as in melanosis oculi. Usually the surface of the iris in iris melanosis is smooth. Iris mammillations are the elevations on the surface of the iris, which may be associated with naevi or iris melanosis but are not in themselves a pigmentary condition. ${ }^{7}$

Iris mammillations appear to be more common in pigmented races: four of our cases were hispanic, two Indian, one Iranian, one North African and only one Caucasian, although this may reflect the referral population. They were familial in one case where a mother and daughter were affected. There was coexistent intraocular pathology in some cases: 4 of the 8 cases had melanosis oculi, 1 of which was in association with neurofibromatosis type 1,1 with phakomatosis pigmentovascularis (PPV) type IIb and 1 with a ciliary body mass. In those individuals without melanosis oculi, there was presumably unrelated ocular pathology: one girl had high myopia possibly in association with a Stickler phenotype, and another girl had optic neuritis. Only 1 patient had congenital glaucoma and this was the patient with PPV type IIb.

Melanosis oculi with or without iris melanosis is thought to be a premalignant condition associated with a higher incidence of intraocular melanoma of between $10 \%$ and $25 \%{ }^{1,5,8}$ This has, however, been disputed by Blodi ${ }^{21}$ who reported a case of melanosis oculi in one eye and malignant uveal melanoma in the other unaffected eye. It has been suggested that iris mammillations (called iris melanosis in one article $^{8}$ ) and melanosis oculi are variants of the same condition and that iris mammillations are also a premalignant condition. ${ }^{5,8}$ In almost all cases of associated intraocular tumour there is probably coexistent melanosis oculi, which may be the more important aetiological factor. $5,10,13,22,23$

The inheritance of iris mammillations appears to be varied. Most cases of iris mammillations are sporadic, our case 6 demonstrates that they may be dominantly inherited, and some previously published cases imply recessive inheritance. ${ }^{7}$ When iris mammillations are found in association with melanosis oculi, the inheritance pattern is also most commonly sporadic. However, they may be dominantly inherited as in our case 6 and in the case described by Kiewe. $^{24}$ They are less likely to be recessively inherited even though consanguinity was descibed in two families. ${ }^{2,24}$

Key words: Iris mammillations, Iris melanosis, Iris nodules, Melanosis oculi.

\section{REFERENCES}

1. Coats G. Unilateral diffuse melanosis of the uvea, with small elevations on the surface of the iris. Trans Ophthalmol Soc UK 1912;32:164-71.

2. Fleischer B. Zwei Fälle von einseitiger Melanosis der Sklera, der Iris und des Augenhintergrundes mit warzenförmigen, kleinen Erhebungen an der Iris vorderfläche. Klin Monatsbl Augenheilkd 1913;51: $170-4$.

3. Waardenburg PJ. Heterochromie en melanosis. Ned T Geneesk 1918;62:1453-5.

4. Friedenwald H, Friedenwald JS. Melanosis of the lids, conjunctiva, and sclera, with wart-like growths on the iris. Arch Ophthalmol 1925;54:51-4.

5. François J. La mélanose congénitale et bénigne de l'oeil. Arch d'Ophtalmol 1934;51:689-718,776-92.

6. François J. Heredity in ophthalmology. St Louis: CV Mosby, 1961:532-4.

7. Joondeph BC, Goldberg MF. Familial iris melanosis: a misnomer? Br J Ophthalmol 1989;73:289-93.

8. Traboulsi EI, Maumenee IH. Bilateral melanosis of the iris. Am J Ophthalmol 1987;103:115-6.

9. Gilliam AC, Ragge NK, Perez MI, Bolognia JL. Phakomatosis pigmentovascularis type IIb with iris mammillations. Arch Dermatol 1993;129:340-2.

10. Hulke JW. A series of cases of carcinoma of the eyeball. R Lond Ophthal Hosp Rep 1861;3:279-86.

11. Leibreich R. Ophthalmosk. Atlas. In: Pigmentierter Optikus bei sogenannter Cyanosis bulbi. 1863: plate 12, figure 3.

12. Manz. Melanosis oculi. In: Graefe A, Saemisch T. Handbuch der gesammten Augenheilkunde II. Leipzig, 1876:117-9.

13. Collins ET. Case of a patient with congenital excess of pigment in the uveal tract and pigmentation of the sclerotic in one eye, which late in life became the seat of a melanotic sarcoma. Trans Ophthalmol Soc UK 1894;14:197-9.

14. Terson MA. Mélanochromie congénitale de la sclérotique. Ann d'oculist 1904;131:127-8.

15. Hirschberg J. Ueber die angeborene Pigmentirung der Sclera und ihre pathogenetische Bedeutung. Graefes Arch Ophthalmol 1883;29:1-12.

16. Ragge NK, Falk RE, Cohen WE, Murphree AL. Images of Lisch nodules across the spectrum. Eye 1993;7:95-101.

17. Bourquin J. Die angeborene Melanose des Auges. Z Augenheilkd 1917;37:129-74, 294-311.

18. Mann I. Developmental abnormalities of the eye, 2nd ed. London: William Clowes and Sons, 1957:290-1.

19. Collins ET. Unilateral melanosis of the uvea and sclera, with numerous small elevations on the surface of the iris. Trans Ophthalmol Soc UK 1912;32:171-3.

20. Lisch K. Ueber Beteiligung der Augen, insbesondere das Vorkommen von Irisknötchen bei der Neurofibromatose (Recklinghausen). Z Augenheilkd 1937;93: 137-43.

21. Blodi FC. Ocular melanocytosis and melanoma. Am J Ophthalmol 1975;80:389-95.

22. Jay B. Malignant melanoma of the orbit in a case of oculodermal melanosis. Br J Ophthalmol 1965;49: 359-63.

23. Font RL, Reynolds AM, Zimmerman LE. Diffuse malignant melanoma of the iris in the nevus of Ota. Arch Ophthalmol 1967;77:513-8.

24. Kiewe P, Maneff I. Mélanose bilaterale congénitale et familiale de l'oeil et de la face. Contribution au problème de la consanguinité. Ann Oculistique 1935; 172:723-8. 